\title{
Serotonin signaling modulates the effects of familial risk for depression on cortical thickness
}

\author{
Ravi Bansal ${ }^{\mathrm{a}, \mathrm{b}, *}$, Bradley S. Peterson ${ }^{\mathrm{a}, \mathrm{b}}$, Jay Gingrich ${ }^{\mathrm{c}, \mathrm{d}}$, Xuejun Hao ${ }^{\mathrm{c}, \mathrm{d}}$, Zagaa Odgerel ${ }^{\mathrm{c}, \mathrm{d}}$, \\ Virginia Warner $^{c, d}$, Priya J. Wickramaratne ${ }^{c, d}$, Ardesheer Talati ${ }^{c, d}$, Mark Ansorge ${ }^{c, d}$, \\ Alan S. Brown ${ }^{\mathrm{c}, \mathrm{d}}$, Andre Sourander ${ }^{\mathrm{c}, \mathrm{e}}$, Myrna M. Weissman ${ }^{\mathrm{c}, \mathrm{d}}$ \\ a Department of Pediatrics, Keck School of Medicine, Los Angeles, CA 90033, United States \\ ${ }^{\mathrm{b}}$ Institute for the Developing Mind, The Saban Research Institute, CHLA, CA 90027, United States

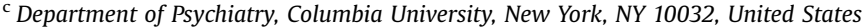 \\ d New York State Psychiatric Institute, New York, NY 10032, United States \\ e Department of Child Psychiatry, University of Turku, Turku, Finland
}

\section{A R T I C L E I N F O}

\section{Article history:}

Received 14 May 2015

Received in revised form

7 November 2015

Accepted 3 January 2016

Keywords:

Structural MRI

Imaging Genetics

Serotonin

Familial Risk

Major Depressive Disorder

Heritability

\begin{abstract}
A B S T R A C T
Depression is a highly familial and a heritable illness that is more prevalent in the biological offspring of the depressed individuals than in the general population. In a 3-generation, 30-year, longitudinal study of individuals at either a high(HR) or a low(LR) familial risk for depression, we previously showed cortical thinning in the right hemisphere was an endophenotype for the familial risk. In this study, we assessed whether the effects of familial risk were modulated by the serotonin-transporter-linked polymorphic region (5-HTTLPR). We measured cortical thickness using MRI of the brain and associated it with 5-HTTLPR polymorphism in $76 \mathrm{HR}$ and 53 LR individuals. We studied the effects of genotype and geneby-risk interaction on cortical thickness while controlling for the confounding effects of age and gender, and for the familial relatedness by applying a variance component model with random effects for genotype. The results showed significant effects of gene-by-risk interaction on thickness: The "s" allele was associated with thinner cortex in the LR individuals whereas with thicker cortex in the HR individuals. The opposing gene effects across the two risk groups were likely due to either epistatic effects and/or differing modulation of the neural plasticity by the altered 5-HT signaling in utero.
\end{abstract}

(c) 2016 Elsevier Ireland Ltd. All rights reserved.

\section{Introduction}

Heterogeneous symptom presentations of depression across individuals are likely caused by pathological environmental factors interacting with genetic and/or epistatic factors interacting with. To understand the moderating effects of genetic factors, we associated serotonin-linked, functional polymorphism with cortical thickness in 129 individuals who were at either at a high or a low familial risk for depression and were recruited as a part of an ongoing, 3-generation, 30-year, longitudinal study (Weissman et al., 2005a; Weissman et al., 2006). The probands in this study formed the generation 1 (G1) who either had severe, debilitating Major Depressive Disorder (MDD) or did not have any lifetime history of MDD. In the following we interchangeably used "depression" with MDD. The children (generation 2, G2) and

\footnotetext{
* Corresponding author at: Department of Pediatrics, University of Southern California, 4661 Sunset Boulevard, Mailstop\# 135, Los Angeles, CA 90027, United States.

E-mail address: rabansal@chla.usc.edu (R. Bansal).
}

grandchildren (generation 3, G3) of the probands with depression were at a high familial risk (HR) whereas those of the probands without depression were at a low familial risk (LR) for depression. Previously (Peterson et al., 2009) we had identified thinner cortex in the HR individuals across large portions of right lateral (post and precentral gyrus, inferior parietal lobe, middle and inferior occipital lobe, middle and inferior frontal gyrus, and posterior regions of the superior and middle temporal gyrus) and the left mesial (subgenual cortex, cuneus, precuneus, posterior cingulate, post and precentral gyrus, anterior cingulate, and superior frontal gyrus) hemispheres as a risk endophenotype (Peterson et al., 2009) because cortical thinning was present in the HR individuals irrespective of their lifetime history of depression. Similar spatial pattern of cortical thinning were recently reported in children prenatally exposed to depression (Sandman et al., 2015). However, the effects of genetic and/or epistatic factors and moderation of the effects of familial risk by these factors on brain circuits of mood and cognition remain unknown.

Genetic factors that modulate or moderate risk for depression can be identified by assessing their effects on brain abnormalities 
that have been previously implicated in depression. Previous neuroimaging studies of depression have implicated abnormalities in the morphology, activity, and connectivity within and across brain circuits that regulate mood, cognition, sleep, and behavior. Reductions in gray matter volumes have been reported in the amygdala (Hamilton et al., 2008; Altshuler et al., 2010), frontal cortex, orbitofrontal cortex, cingulate cortex (Bora et al., 2012), hippocampus (Cole et al., 2011), striatum (Choi et al., 2008; Lorenzetti et al., 2009), and right lateral and left mesial hemispheres (Peterson et al., 2009). Resting state BOLD fMRI studies in depression have found decreased functional connectivity between the anterior cingulate cortex (ACC) and the thalamus (Anand et al., 2005), decreased corticolimbic connectivity (Anand et al., 2007), decreased connectivity between the anterior cingulate cortex and the amygdala (Anand et al., 2009), increased functional connectivity in the dorsomedial prefrontal cortex (DMPFC) (Sheline et al., 2010), and decreased connectivity with the caudate nucleus (Bluhm et al., 2009). Taken together, imaging studies have identified disturbances in brain circuits of mood and cognition that underlie pathophysiology of depression. Associating these disturbances with functional polymorphism of genes linked to depression would identify genetic and/or epigenetic factors that moderate individual's risk for depression.

Several genes have been associated with depression, especially those that alter serotonin signaling, including serotonin-transporter-linked polymorphic region (5-HTTLPR) of the serotonin (5HT) gene SLC6A4 that codes the serotonin transporter(5-HTT) (Caspi et al., 2003), brain-derived neurotrophic factors (BDNF) (Lee and Kim, 2010; Masi and Brovedani, 2011), tryptophan hydroxylase-2 (TPH2) (Gao et al., 2012), monoamine oxidase A (MAO-A) (Tzeng et al., 2009), and serotonin receptor 2A (HTR2A) (Antypa et al., 2013). These genes either directly modulate serotonin(Mann, 1999) signaling or interact with other genes to alter neuroplastic response of the brain. The long " $L$ " and the short " $s$ " functional variants (Heils et al., 1995) of the 5-HTTLPR have received great attention because the " $s$ " allele has been associated with decreased transcription efficiency of the 5-HTT gene(Lesch and Mossner, 1998), thereby decreasing the density of 5-HTT in presynaptic neurons and increasing the intensity and duration of the serotonin signaling (Glatz et al., 2003). However, because several large studies have failed to associate the 5-HTTLPR polymorphism with depression (Caspi et al., 2003), this polymorphism may only moderate the influence of stressful life events and when exposed to stressful life events, individuals with the "s" allele could be at a greater risk for developing depression than those with the "L" allele (Caspi et al., 2003; Eley et al., 2004; Kendler et al., 2005; Wilhelm et al., 2006; Zalsman et al., 2006).

Imaging genetic studies associated the 5-HTTLPR polymorphism with altered function and morphology of brain regions and circuits that modulate mood and cognition. The fMRI studies showed that individuals with the "s" allele exhibited amygdala hyperactivity in response to threatening stimuli (Hariri et al., 2002; Heinz et al., 2005; Hariri et al., 2005) because of the disrupted regulation (Hariri et al., 2005) of amygdala response by the perigenual anteriror cingulate cortex (pACC) (Hariri et al., 2005). Anatomical MRI studies showed that individuals who had the " $\mathrm{s}$ " allele had decreased gray matter volumes in the pACC and the amygdala (Pezawas et al., 2005), regions intimately involved in emotional response (Pezawas et al., 2005) and mood. These alterations in brain function and morphology could be due to the morphological consequences of the altered serotonin signaling in fetus during brain development (Ansorge et al., 2004; Esaki et al., 2005; Homberg et al., 2010). We therefore expected these morphological consequences to be present in individuals who were at a greater risk for developing depression, regardless of their lifetime history for depression. Because the "s" allele has been associated with increased vulnerability for developing depressive symptoms(Caspi et al., 2003) and because the risk endophenotype (Peterson et al., 2009) was not a consequence of illness and/or medication use, we hypothesized that individuals who had at least one "s" allele would have thinner cortex in the brain regions of risk endophenotype compared to those who had the homozygous $\mathrm{L} / \mathrm{L}$ genotype.

\section{Methods}

\subsection{Participants}

We acquired brain MR images in 129 individuals, ages 6 to 54 years, in generation 2 (G2) and generation 3 (G3), who were biological descendents of the probands (generation 1, G1) recruited in an ongoing, 30-year, longitudinal study (Weissman et al., 2005a; Weissman et al., 2006). The probands (G1) were white Caucasians and either had moderate to severe MDD with more than one episode of moderate to severe depression of 4 week duration or had no lifetime history of any psychiatric illness over an eight-year period. The probands with MDD were selected from outpatient clinic for the psychopharmacologic treatment of MDD and the nondepressed probands were selected from the same community (Weissman et al., 1987). The biological descendants of the probands with depression were at a high familial risk (HR) for depression, whereas those of the probands without depression were at a low familial risk (LR) for depression. Since the previous study (Peterson et al., 2009) with 131 individuals, we had processed MRI data for additional 16 individuals in generations $2 \& 3$. Of these 147 individuals, present study comprised 129 individuals who had both MRI and genotype data, with 113 individuals in both the previous (Peterson et al., 2009) and the present study. The HR group consisted of 76 individuals ( 61 adults age $>=18$ years; 43 females; mean age 33.80 years [SD 13.06]; 26 individuals had the homozygous L/L genotype and 38 had the heterozygous s/L genotype) and the LR group consisted of 53 individuals ( 28 adults age $>=18$ years; 26 females; mean age 24.86 years [SD 13.27]; 17 individuals had the homozygous L/L genotype and 35 had the heterozygous s/L genotype). All participants were white Caucasian. Although the HR and LR groups did not differ by gender and the 5-HTTLPR allele frequency, during a 20-year follow-up the HR individuals compared to the LR individuals had threefold higher risk for mood disorder, lower age-at-onset of MDD, (Weissman et al., 2006) and significantly greater frequency of lifetime depression ( Table 1). Few participants at scan time had comorbid disorders: 3 LR individuals and 5 HR individuals had Generalized Anxiety disorder, 5 LR and 10 HR individuals had Panic Disorder, 4 LR and 1 HR individual had Attention Deficit Disorder, and 4 LR and $4 \mathrm{HR}$ individuals had Obsessive Compulsive Disorder. However, all participants at the scan time were free of current depression and medication use. The interviews were conducted at each of the five waves in the longitudinal study: At baseline and years $2,10,20$, and 25 of the study. We currently are completing the 6 th wave at 30 year in the study. The diagnostic assessments for the analyses were carried out at the 5th wave within one week of the MRI scan and the lifetime diagnoses used in the analysis were cumulative over all the previous waves. That is, the final diagnosis included diagnoses from all five waves of the longitudinal study and was based on a best-estimate procedure that involved an independent review of all assessments, including the assessment at MRI scan, by 2 experienced clinicians-a child psychiatrist or a psychologist. The expert clinicians were not involved in the interviewing and were blind to the diagnostic status of the previous generations, MRI scan, and genotype of the participants (Leckman et al., 1982). 
Table 1

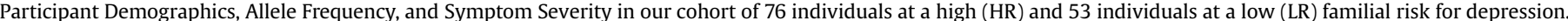

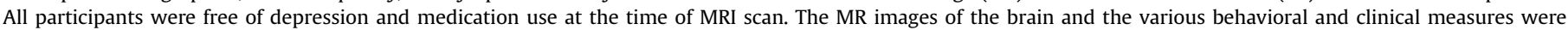

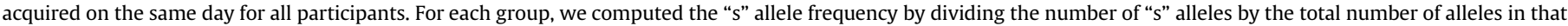

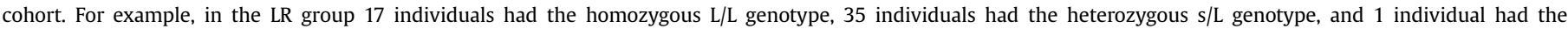

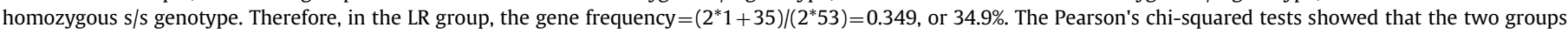
did not differ on gender or the frequency of the " $s$ " allele.

\begin{tabular}{|c|c|c|c|}
\hline & High risk (HR) & Low risk (LR) & Statistics \\
\hline Number of participants & 76 & 53 & \\
\hline Percent with lifetime Depression & $55.3 \%$ (42 individuals) & $20.7 \%$ (11 individuals) & $\chi^{2}=15.362, \mathrm{~d} f=1, P$-value $=0.0001$ \\
\hline Gender & 43 Females & 26 Females & $\chi^{2}=0.710, \mathrm{~d} f=1, P$-value $=0.3994$ \\
\hline $\begin{array}{l}\text { Age (Years) } \\
\text { "s" Frequency }\end{array}$ & $\begin{array}{l}33.80 \pm 13.06 \\
40.8 \%\end{array}$ & $\begin{array}{l}24.86 \pm 13.27 \\
34.9 \%\end{array}$ & $\begin{array}{l}t \text {-stat }=-3.791, \mathrm{~d} f=111, P \text {-value }=0.0002 \\
\chi^{2}=0.914, \mathrm{~d} f=1, P \text {-value }=0.3390\end{array}$ \\
\hline $\begin{array}{l}\text { Current depression (HamD) } \\
\text { Current anxiety (HamA) }\end{array}$ & $\begin{array}{l}5.27 \pm 6.21 \\
5.00 \pm 5.47\end{array}$ & $\begin{array}{l}3.73 \pm 4.91 \\
3.69 \pm 4.53\end{array}$ & $\begin{array}{l}t \text {-stat }=-1.167, \mathrm{~d} f=62, P \text {-value }=0.2474 \\
t \text {-stat }=-1.094, \mathrm{df}=60, P \text {-value }=0.2782\end{array}$ \\
\hline
\end{tabular}

Diagnostic assessment across all waves (Weissman et al., 2005a) included a semistructured diagnostic instrument (the Schedule for Affective Disorders and Schizophrenia-Lifetime Version for adults, and a child version of the instrument for participants 6 to 17 years of age) (Weissman et al., 2005a; Weissman et al., 2006; Peterson et al., 2009; Mannuzza et al., 1986). We also measured current depressive symptoms in children and adults using the Children's Depression Rating Scale-Revised (Poznanski et al., 1985) or the Hamilton Depression Rating Scale (Hamilton, 1967), respectively, and current anxiety symptoms in children and adults using the Revised Children's Manifest Anxiety Scale (Perrin and Last, 1992) or Hamilton Anxiety Rating Scale (Hamilton, 1959), respectively, on the day of MRI scan.

\subsection{Genotyping}

DNA was extracted from saliva sample collected using Oragene DNA Self Collection Kit following a protocol provided by the manufacture (Oragene Genotek, Ontario, Canada). We genotyped the 5-HTTLPR by amplifying the promoter region of the 5-HTT gene with primers (forward: 5'-TCCTCCGCTTTGGCGCCTCTTCC-3'; reverse 5'-TGGGGGTTGCAGGG GAGATCCTG-3') via a polymerase chain reaction (PCR) in multiplex master mix (Qiagen, CA) (Wendland et al., 2006). Amplicon was resolved on a $2.3 \%$ UltraPure $^{\mathrm{TM}}$ Agarose (Invitrogen, Carlsbad, CA), and visualized under the UV transilluminator. Finally, we labeled the 512 nucleotide basis pairs (bps) band as the "L" allele and the 469 bps band as the "s" allele at the 5-HTTLPR(Wendland et al., 2006) region.

\subsection{MRI Scanning}

We obtained $1.17 \times 1.17 \times 1.2 \mathrm{~mm}^{3}$ resolution anatomical MRI scans on a Siemens Sonata 1.5 T scanner (Siemens AG) using a 3DMPRAGE sequence: Repetition Time(TR $=24 \mathrm{msec}$; Echo Time $(\mathrm{TE})=2.96 \mathrm{msec} ;$ Flip Angle $(\mathrm{FA})=45^{\circ}$; Matrix size $=256 \times 192$; Field of View $(F O V)=30 \mathrm{~cm}$; Phase Field of View $=100 \%$; Number of Excitations $(\mathrm{NEX})=2$, Slice Thickness $=1.2 \mathrm{~mm}$; and 124 contiguous slices encoded for sagittal slice reconstruction.

\subsubsection{Preprocessing}

We applied an N3 algorithm (Sled et al., 1998) to correct for large-scale variations in image intensity and removed extracerebral tissues using an automated tool for extracting the brain (Shattuck and Leahy, 2002). We subsequently removed the connecting dura manually on each slice in the sagittal and coronal views.

\subsubsection{Segmenting cortical gray matter}

We used a semi-automated method for segmenting the brain tissue as gray or white matter where an expert neuroanatomist first sampled the gray-scale values of both cortical gray matter and white matter at four standard locations throughout the brain. The sampled values were averaged to generate mean values for gray matter and white matter, which were used to threshold and generate initial tissue segmentation. The initial segmentation was subsequently hand edited in the coronal and transverse views to remove subcortical gray matter and to provide the most accurate segmentation of the cortical mantle. The intraclass correlation ICC (Shrout and Fleiss, 1979) for defining the cortex was greater than 0.98 .

\subsubsection{Mapping cortical thickness}

We mapped cortical thickness of each participants on a template brain by applying the following procedures(Bansal et al., 2005). First, we coregistered the brains to an appropriately selected template brain(Plessen et al., 2006) using a similarity transformation. Second, we applied a high-dimensional, nonrigid warping algorithm based on the dynamics of fluid-flow to warp each brain to the exact size and shape as the template brain. Third, we applied a 3D morphological operator to distance transform the coregistered brain without the cortex (Rosenfeld and Kak, 1982; Haralick and Shapiro, 1992) and calculated cortical thickness as the smallest distance of each point on the external cortical surface from the outermost surface of the white matter. Because cortical thickness was computed in participant brains scaled to the template brain, thicknesses measures were scaled for the generalized scaling effects within the cerebrum. Finally, we displayed statistical results for cortical thickness on the high-resolution, singleparticipant template (http://www.loni.usc.edu/atlases/Atlas_De tail.php?atlas_id=5) from International Consortium for Brain Mapping(ICBM) (Mazziotta et al., 2001). This high-resolution, structural brain template was the average of 27 T1-weighted MRI acquisitions from a single subject in Montreal Neurological Institute database. The template was aligned within the stereotaxic space of the ICBM average template derived from that of Talairach and Tournoux (1988).

\subsection{Statistical Analysis}

At each point on the surface of the template brain we applied linear mixed model to assess the effects of the genotype, gene-byrisk interaction, and measures of current anxiety and depression, while controlling for age and gender and familial risk as appropriate. Because only very few individuals had a comorbid disorder at the scan time, we did not include comorbidity as a covariate in statistical analyses. We assessed the effects of the genotype in each risk group separately and in the subset of HR and LR individuals who did not have lifetime history of MDD. To assess whether the 


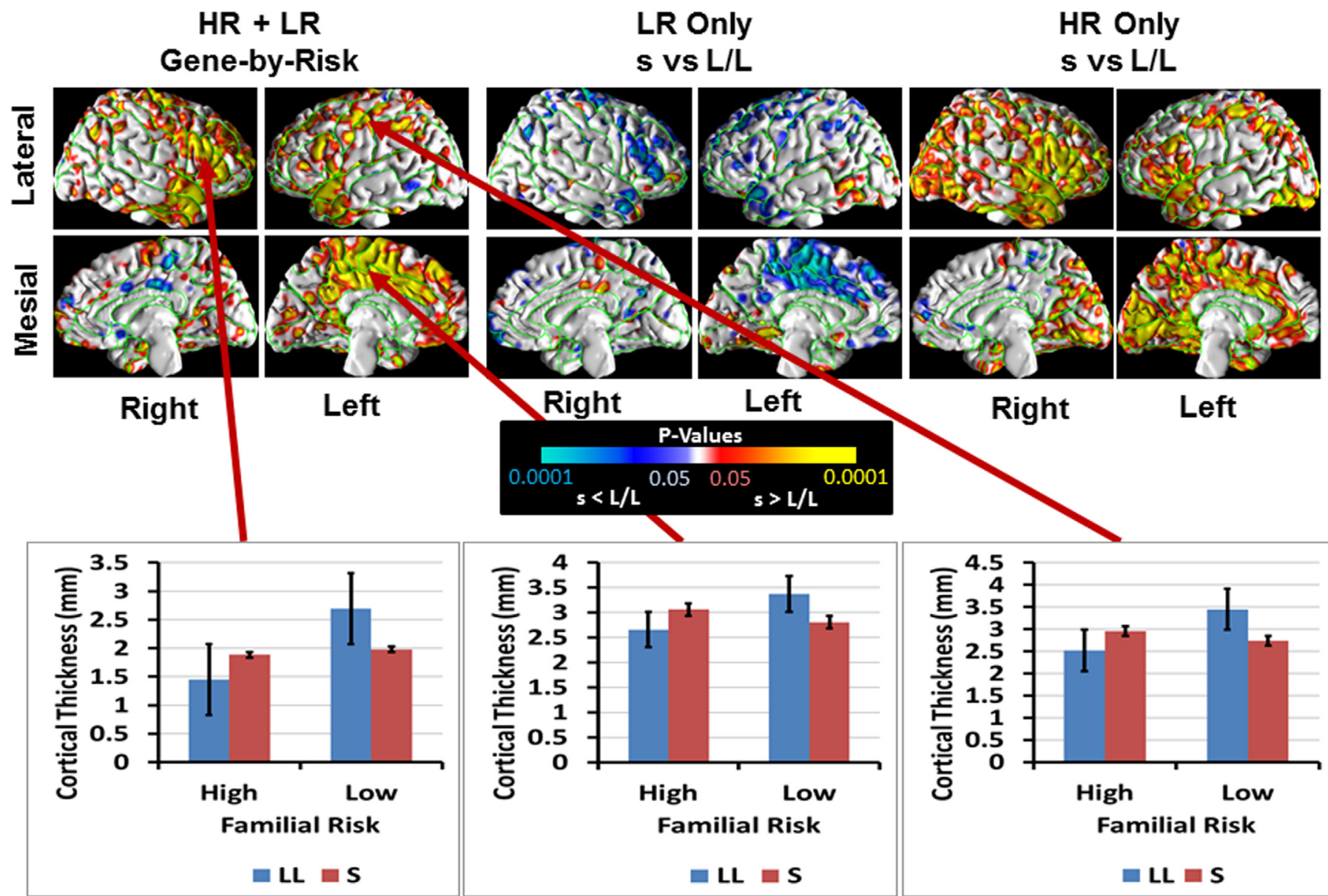

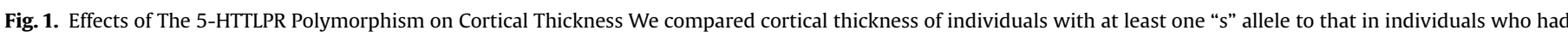

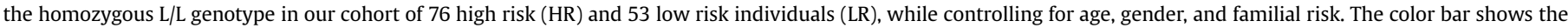

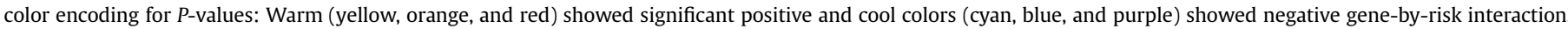

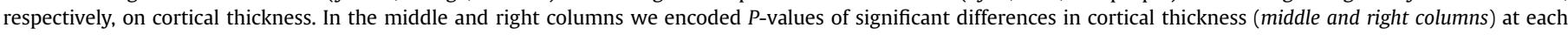

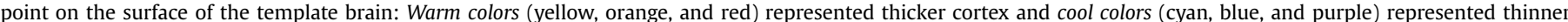

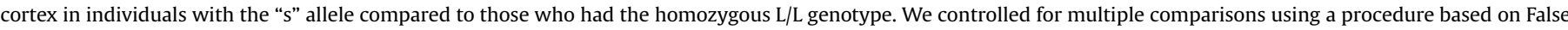

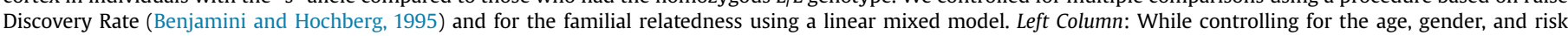

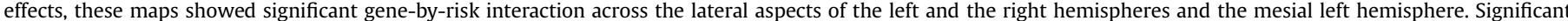

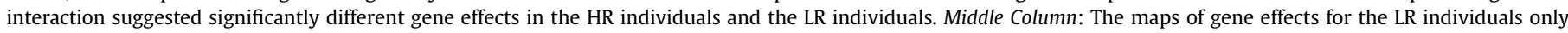

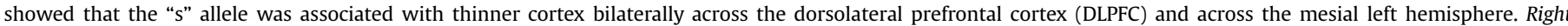

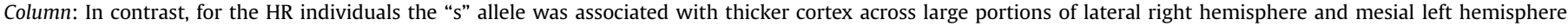

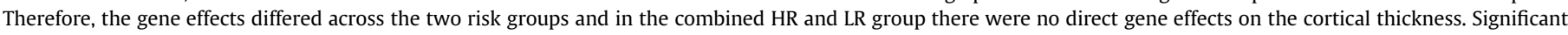

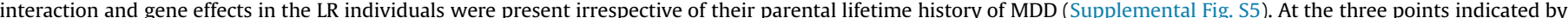

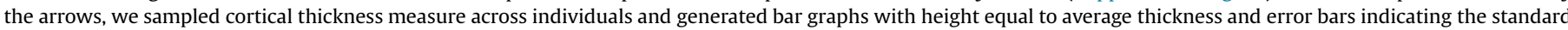

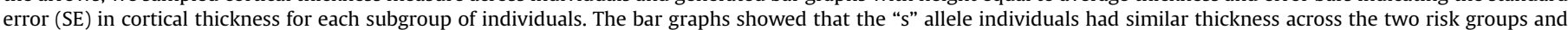

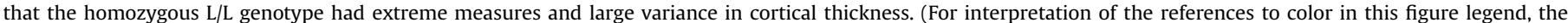
reader is referred to the web version of this article.)

risk endophenotype was present within individuals who had the "s" allele and within individuals who had the homozygous L/L genotype, i.e. the presence of risk endophenotype irrespective of the genotype, we compared cortical thickness between the HR and the LR individuals who had the homozygous L/L genotype and between the HR and the LR individuals with at least one "s" allele. We also assessed whether the 5-HTTLPR genotype modified the risk endophenotype by comparing cortical thickness of $\mathrm{HR} / \mathrm{s}$, and separately HR/ll, individuals with that in the entire cohort of LR individuals. Furthermore, we assessed whether the variance in cortical thickness differed between the two risk groups across the individuals who had the homozygous L/L genotype or at least one "s" allele. In our analyses we grouped individuals who had either the homozygous $\mathrm{s} / \mathrm{s}$ or the heterozygous $\mathrm{s} / \mathrm{L}$ genotype as individuals with at least one "s" allele because only one LR individual and eleven HR individuals had the homozygous s/s genotype.
Combining individuals with the homozygous s/s or the heterozygous $\mathrm{s} / \mathrm{L}$ genotype also is supported by prior imaging genetics studies that found the "s" allele to increase the risk for depression (Caspi et al., 2003), abnormal brain function (Hariri et al., 2002; Hariri et al., 2005; Pezawas et al., 2005) and structure (Kobiella et al., 2011). However, within the HR individuals we assessed the dose-response effects of the "s" allele on the cortex. We could not assess the dose-response effect within the LR individuals because only one LR individual had the homozygous s/s genotype. In all these analyses we color encoded and plotted the $P$-value at each voxel across the entire surface of the template brain.

We controlled for the familial relatedness by incorporating a variance component model of random effects gi (Zhu et al., 2008), a widely implemented model for quantitative genetics (Amos, 1994). The measures of cortical thickness and symptom severity for members within a family are correlated and therefore within- 
family variance differs from between-family variance. To control for familial relatedness and differing variances, we used a variance component model for valid statistical inferences. Assuming that there are $n$ families, let $i=1, \cdots, n$ represent the $i$ th family with $m$ family members. The variance component model then described the brain measure $y_{i j}$ for the $j$ th member $\left(j=1, \cdots, m_{i}\right)$ in the family $i$ as $y_{i j}=x_{i j}^{T} \beta+g_{i j}+\varepsilon_{i j}$, where $\beta$ is a vector of unknown parameters, $g_{i}=\left(g_{i 1}, \cdots, g_{i m i}\right)$ is a vector of genetic effects, and $\varepsilon_{i j}$ represents random environmental and measurement errors. The genetic effects were assumed to be independent of the random environmental effects in this model. We assumed the covariance matrix $\operatorname{Cov}\left(g_{i}\right)$ of $g_{i}$ was $2 \Phi_{i} \sigma_{A}+\Delta_{i} \sigma_{D}$, where $\sigma_{A}$ is the additive genetic variance and $\Phi_{i}$ is the matrix of kinship coefficients, $\sigma_{D}$ is the dominant variance, and $\Delta_{i}$ is the matrix of the probability of sharing 2 alleles identical by descent (Thomas, 2004). We maximized a pseudo likelihood function of the variance component model to estimate the unknown parameters, including associations of cortical thickness with the risk status, genotype, risk-bygene interaction while controlling for age and sex effects. The significance of the various effects on the cortex were tested by forming appropriate linear hypotheses of unknown parameters and using score test statistic(Cox and Hinkley, 1979; Lehmann and Romano, 2005) that was asymptotically chi-squared $\chi^{2}$ distributed with appropriate degrees of freedom (Zhu et al., 2008). We corrected for multiple statistical comparisons using a procedure based on false discovery rate (FDR)(Benjamini and Hochberg, 1995; Benjamini, 2010) with FDR set at 0.05.

\section{Results}

Our analyses showed that the direct effects of the 5-HTTLPR polymorphism on cortical thickness were small and sparsely distributed across the entire brain. However, there were significant effects of gene-by-risk interaction on the cortex: In LR individuals who had at least one "s" allele (LR/s), compared with the LR individuals who had the homozygous L/L genotype (LR/ll), the cortex was thinner bilaterally in the middle and inferior frontal gyrus and in the superior frontal gyrus and middle cingulate gyrus in the mesial aspect of the left hemisphere. In contrast, the HR/s individuals had thicker cortex than the HR/ll individuals ( Fig. 1) across large portions of the brain bilaterally, especially in the middle and inferior frontal gyrus, anterior regions of the superior and middle temporal gyrus, and the supramarginal gyrus, and across the entire mesial aspect of the left hemisphere. Controlling for the current symptom severity of depression did not modify the effects of gene-by-risk interaction on the cortex. Thinner cortex in the LR/s individuals compared to the LR/ll individuals supported the hypothesis in LR individuals that the "s" allele is associated with thinner cortex than the homozygous L/L genotype. However, thicker cortex in the HR/s individuals compared to the HR/ll individuals contradicted our a priori hypothesis (Fig. 1). Furthermore, associations of the cortex with the genotype were unchanged by the lifetime history of depression in both the HR individuals ( Fig. 2) and the LR individuals, thereby suggesting that the opposing effect of genotype and thickness was not a consequence of having the depressive illness or of medication use. The dose-response effects of the "s" allele within the HR individuals were weak, likely due to small number of HR individuals who had the homozygous s/s genotype and possibly nonlinear dose response of the "s" allele. To understand better the gene-by-risk effects, we generated bar graphs of cortical thickness measures in the brain region with significant gene-by-risk interaction (Fig. 1). These graphs showed that the LR/s individuals had thinner cortex than the LR/ll individuals and the association was reversed in the HR individuals.

Comparing cortical thickness of the HR/s to LR/s and the HR/ll to $L R / 11$ individuals showed that the risk endophenotype was present in both the HR/s and the HR/ll individuals ( Fig. 3). To understand whether the genotype modified the risk endophenotype, we compared cortical thickness in the HR/ll and the $\mathrm{HR} / \mathrm{s}$ individuals with those in the entire cohort of LR individuals. These analyses showed that although the risk endophenotype was spatially more expansive in the HR/ll individuals and slightly attenuated in the $\mathrm{HR} / \mathrm{s}$ individuals, the risk endophenotype was largely unmodified by the 5-HTTLPR polymorphism: Both alleles were associated with thinner cortex in the right lateral hemisphere and the mesial left hemisphere ( Fig. 4). Similarity of the risk endophenotype across the two alleles suggested that the 5-HTTLPR polymorphism explained only a small part of the variance in cortical thickness within the risk endophenotype.

The bar graphs in the brain regions with significant gene-byrisk interaction showed that cortical thickness in the HR/s individuals did not differ significantly $(P$-values $=0.261,0.179,0.146$ for the three points) from that in the LR/s individuals (Fig. 1). More importantly, the variance in thickness measures for the LR/s individuals were significantly smaller than that for the LR/ll individuals in the dorsolateral prefrontal cortex (DLPFC) region (LR/
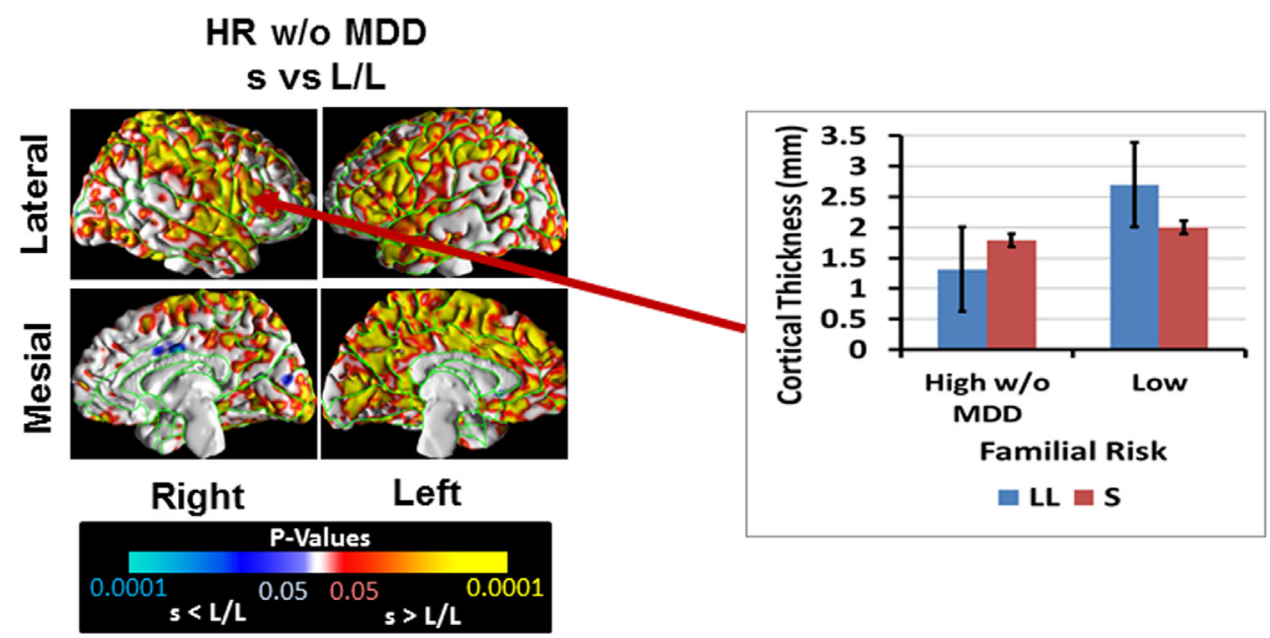

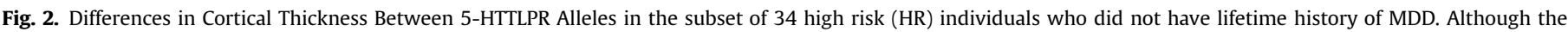

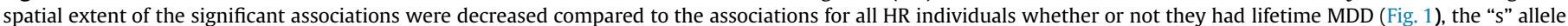
compared to the homozygous L/L genotype was associated with thicker cortex. The color encoding used for $P$-values is the same as that in Fig. 1 . 


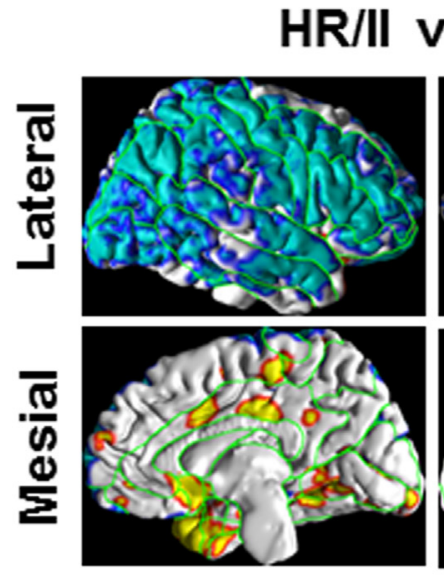

Right vs LR/II

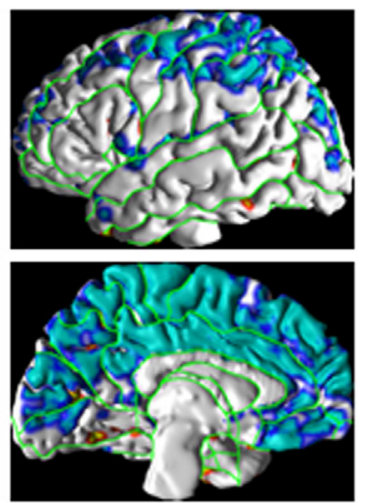

Left
$\mathrm{HR} / \mathrm{s}$ Vs LR/s
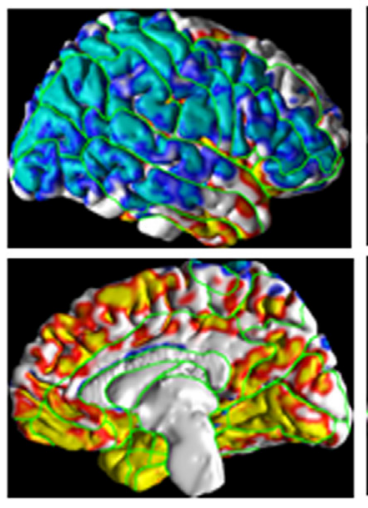

Right
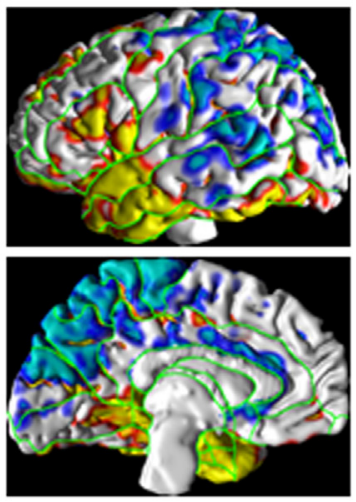

Left

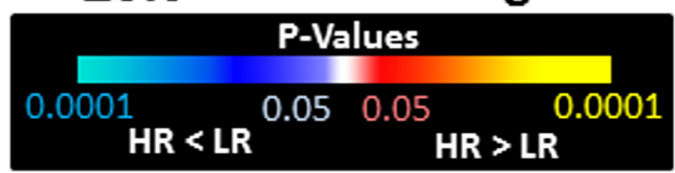

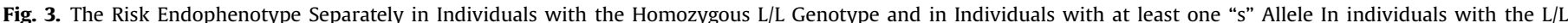

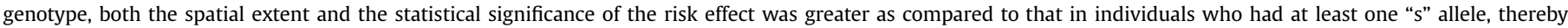
suggesting others genes and/or greater environmental having large effects on risk endophenotype. The color encoding used for $P$-values is the same as that in Fig. 1.

$\mathrm{ll}=1.3, \quad \mathrm{LR} / \mathrm{s}=0.25, \quad$ F-statistic $=5.05, \quad \mathrm{df} 1=16, \quad \mathrm{df} 2=35, \quad P-$ value $=0.00003)$ in the right hemisphere and in the mesial left hemisphere $(\mathrm{LR} / \mathrm{ll}=0.98, \mathrm{LR} / \mathrm{s}=0.5, \quad \mathrm{~F}$-statistic $=1.93, \mathrm{df} 1=16$, $\mathrm{df} 2=35, P$-value $=0.05)$ but not in the left lateral hemisphere $(\mathrm{LR} /$ $\mathrm{ll}=0.56, \quad \mathrm{LR} / \mathrm{s}=0.55, \quad$ F-statistic $=1.02, \quad \mathrm{df} 1=16, \quad \mathrm{df} 2=35, \quad P-$ value $=0.45$ ). The plots of the variance in thickness (Fig. 5 , left and middle columns) showed greater variance in the LR individuals than the HR individuals and that the variance was significantly higher in the individuals who had the homozygous L/L genotype than those with at least one "s" allele. A statistical comparison of the variance across the entire brain, separately in the HR and in the LR individuals, showed that the individuals with L/L genotype had significantly higher variance in the thickness measure compared to that in the individuals who had at least one "s" allele (Fig. 5, right column). Therefore, the bar graphs showed the following. First, the $\mathrm{L} / \mathrm{L}$ individuals in the two groups were at the two

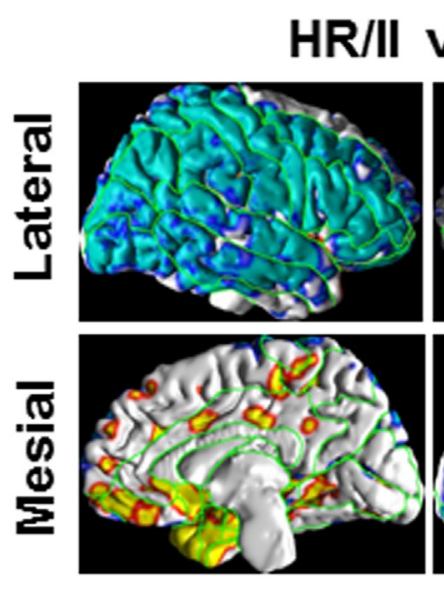

Right
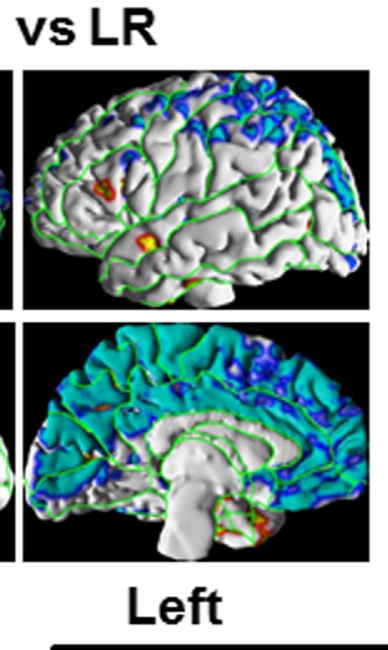
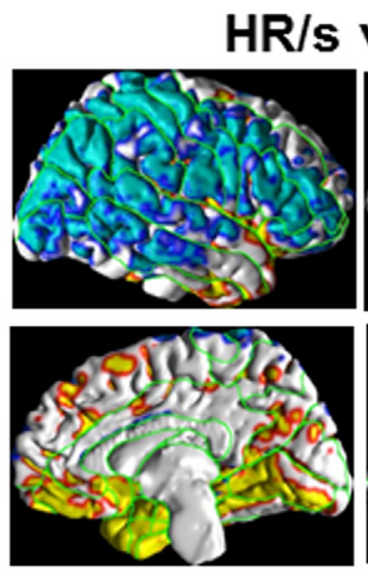

Right
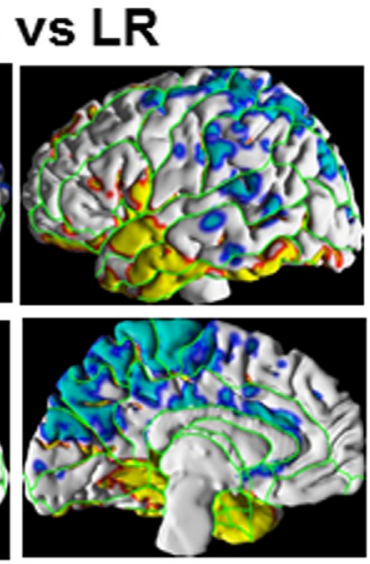

Left

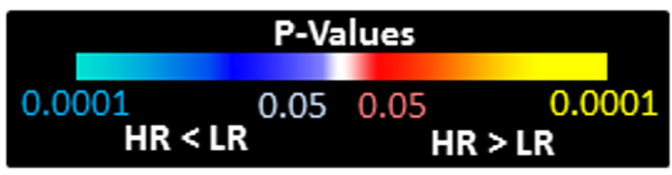

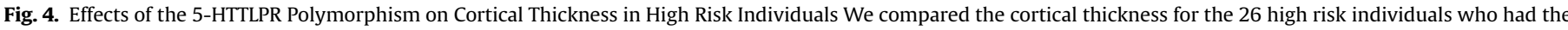

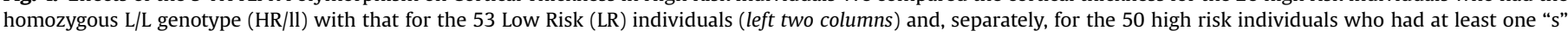

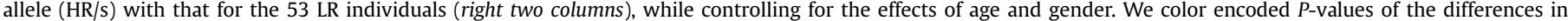

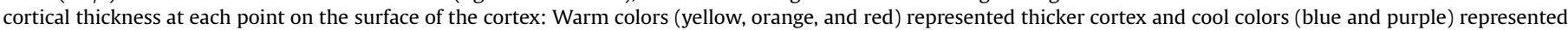

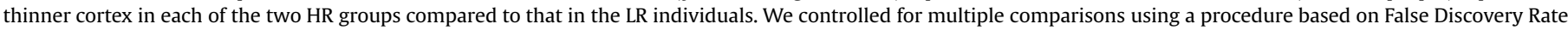

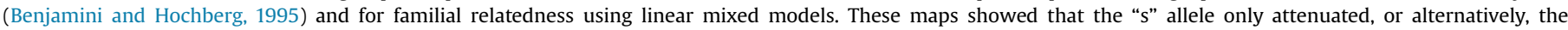

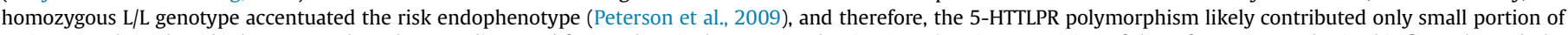

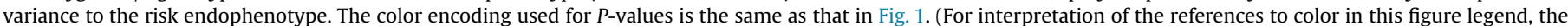
reader is referred to the web version of this article.) 


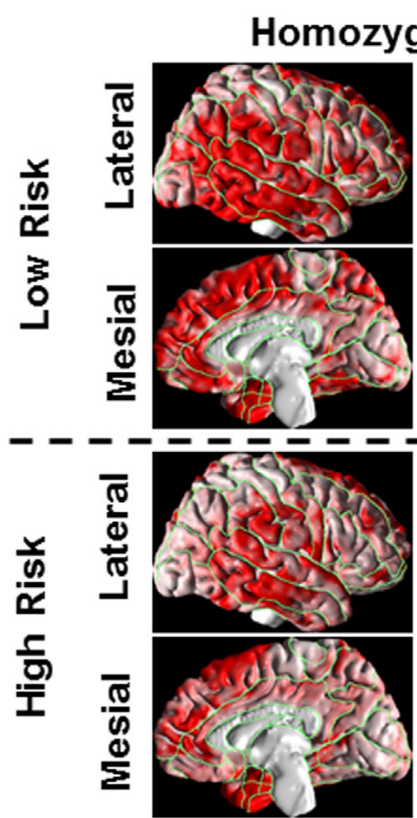

Right gous L/L

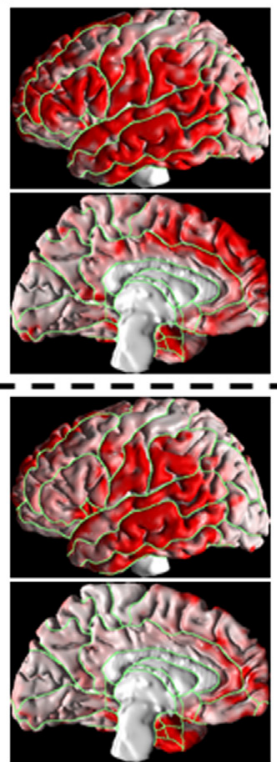

Left

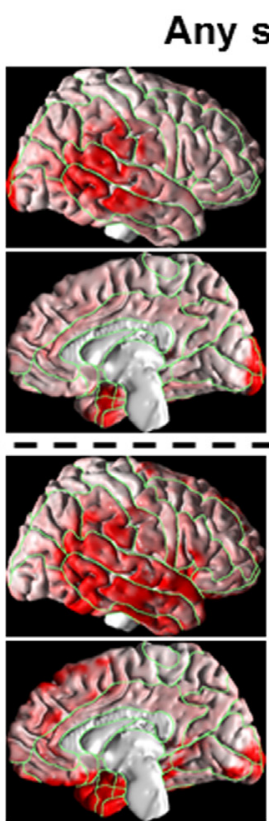

Right s allele

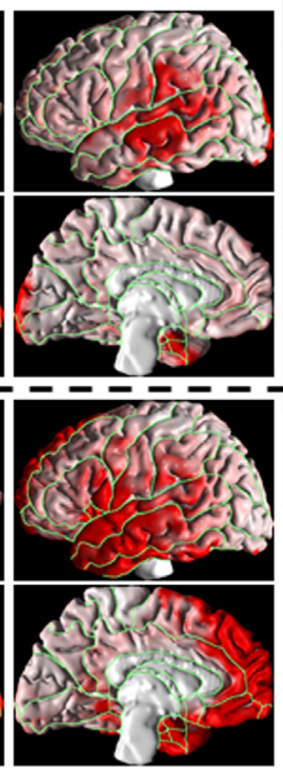

Left

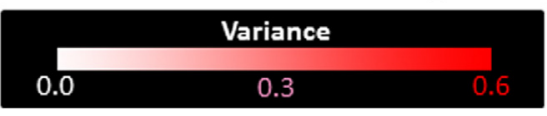

s versus L/L

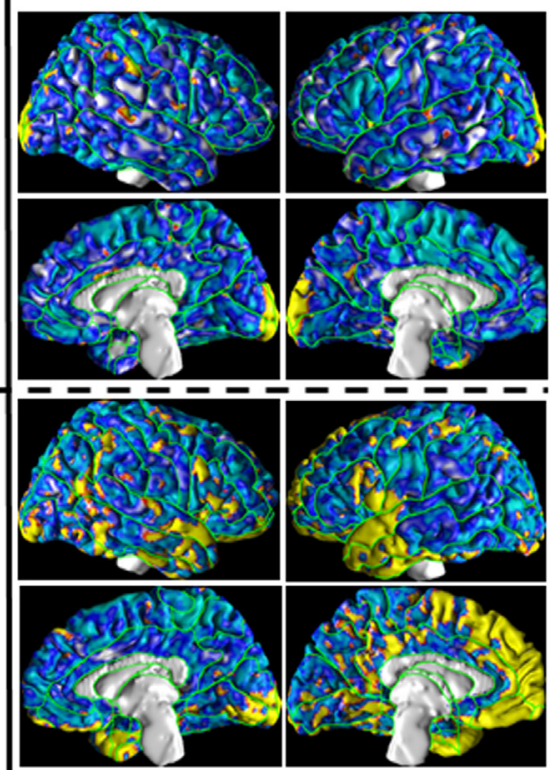

Right

Left

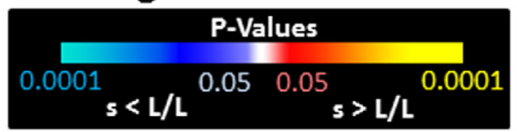

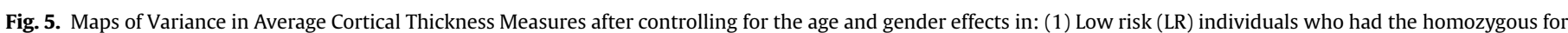

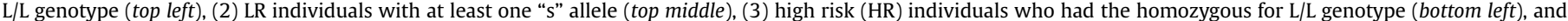

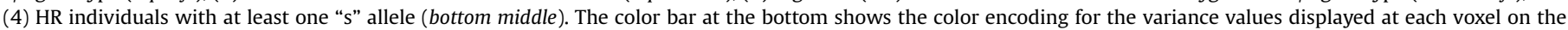

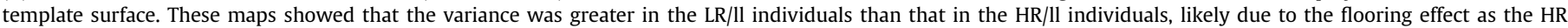

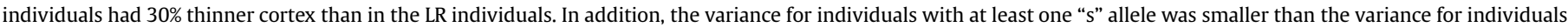

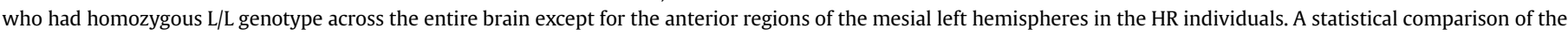

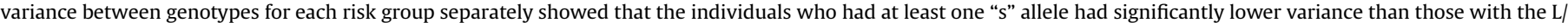
$\mathrm{L}$ genotype (top and bottom right).

opposite ends of the range for cortical thickness with statistically significantly ( $P$-values $=0.0002,0.0022,0.0017$ for the three points) greater thickness in the LR/ll individuals and significantly thinner cortex in the HR/ll individuals. Second, the variance for the "s" allele individuals was significantly lower than that for the homozygous L/L individuals. Third, cortical thickness for the LR/s individuals did not differ significantly from that for the HR/s individuals at locations with significant interactions. Therefore, in individuals with at least one "s" allele, the average thickness did not differ between the two risk groups and the variance was small. In contrast, the $\mathrm{L} / \mathrm{L}$ individuals had greater variances than the "s" allele individuals, with the LR/ll individuals having significantly thicker and the HR/ll individuals having significantly thinner average cortex than that in the "s" allele individuals.

\section{Discussion}

We found that although allelic variation at the 5-HTTLPR polymorphism exerted no direct gene effects on the cortex, that variation did modulate significantly the effects that familial risk for depression has on the cortex, as evidenced by the significant gene-by-risk interaction on cortical thickness (Figs. 1 and 2). The effects of genotype and gene-by-risk interaction in children (15 HR children and 25 LR children) were small and scattered across the entire brain due to insufficient statistical power to detect these associations. The effects, however, were the same for adults (age $>18$ years), suggesting that the age did not moderate the effects of allelic variation on cortical thickness. In the LR group, the individuals who had at least one "s" allele on average had thinner cortex than did those who had the homozygous L/L genotype, providing statistical support for the hypothesis that the "s" allele is associated with cortical thinning. The finding of cortical thinning associated with the "s" allele replicates previously reported association of the "s" allele with reduced gray matter volumes across limbic regions in healthy individuals (Pezawas et al., 2005). In the HR group the gene effects were reversed: The individuals who had at least one "s" allele on average had thicker cortex than did those who had the homozygous L/L genotype. The opposing gene effects were invariant of the lifetime history of depression and explained only a small portion of the variance in the risk endophenotype (Figs. 3 and 4). The opposing gene effects in the HR group were supported by the previous studies (Li et al., 1997; Hu et al., 2000; Zill et al., 2000; Chorbov et al., 2007; Frodl et al., 2008) of individuals with various illnesses that associated increased gray matter volumes with the "s" allele. The opposing gene effects across the two risk groups possibly are due to either epistatic effects, differing functional consequence of the polymorphism in the HR individuals, and/or a greater role of environmental stressors on the cortex in presence of the L/L genotype. The plots of variance in thickness showed lower variance of thickness measures in the participants who had at least one "s" allele, suggesting that the opposing findings of the genotype in the two risk groups could be due to blunted neuronal plasticity in individuals who had the " $\mathrm{s}$ " allele. Furthermore, the 5-HTTLPR polymorphism only moderated the risk endophenotype, and is likely that other genetic, epistatic, and/or environmental factors had larger contribution to the variance of cortical thickness within the endophenotype. Thus, the 
findings suggested that the 5-HTTLPR polymorphism likely modulated the effects of familial risk on thickness by modulating neuronal plasticity.

\subsection{The Serotonin Paradox}

Decreased serotonin signaling has been widely implicated in the pathophysiology of depression. Commonly used antidepressant medications, such as SSRIs and MAO-I, increase serotonin signaling either by blocking the reuptake of serotonin into presynaptic neurons (White et al., 2005) or by inhibiting the activity of MAO-A and prevent the metabolism of serotonin in the synaptic cleft. Similar to antidepressant medications, the "s" allele increases serotonin signaling by decreasing serotonin transporter (5-HTT) density (Heils et al., 1996) in presynaptic neurons: Therefore, the "s" allele should decrease the vulnerability to developing depression. However, the "s" allele has been associated with increased vulnerability to depression when exposed to adverse life events (Caspi et al., 2003). The paradoxical effects of increased serotonin signaling could be due to morphological consequence of altered signaling in the developing brain. Animal studies (Whitakerazmitia and Azmitia, 1986; Haydon et al., 1987; Goldberg, 1998) have shown that serotonin plays an autoregulatory role in developing brain, such that increased signaling inhibits the outgrowth of the serotonergic neurons. Decreased outgrowth subsequently has been associated with depressive (Lira et al., 2003) and anxious (Holmes et al., 2003) behaviors in 5-HTT knock-out mice (Ansorge et al., 2008). Increased serotonin signaling in the developing brain therefore may lead to morphological changes that alter neuroplasticity and subsequently predispose an individual to a higher risk for developing depression.

\subsection{Gene-by-risk interaction}

The effects of the two 5-HTTLPR alleles differed in the HR and the LR groups: The "s" allele was associated with cortical thinning in the LR group but with cortical thickening in the HR group. The statistical main effects of the allelic variations were small and sparsely distributed across the entire brain because of the opposing effects of the 5-HTTLPR polymorphism in the two risk groups. The significant gene-by-risk interaction and gene effects were present irrespective of the parental lifetime history of depression in the LR individuals of G3 (Supplemental Fig. S5) because of several factors, including: (1) The parents themselves were LR individuals with high scores $(>70)$ on Global Assessment Scale (GAS) (Endicott et al., 1976; Shaffer et al., 1983), except for one parent with the GAS score of 67 (Weissman et al., 2005b). The GAS scores of $<50$ represent serious impairment in social, occupational, and school functioning. The parental depression of the G3 LR individuals was mild and the parents would not qualify as depressed according to the strict criteria used to recruit the depressed probands in the longitudinal study. (2) The small number of LR individuals with parental depression limited our ability to model accurately the moderating effects of parental depression on the gene effects. The findings in the LR group are supported by prior studies (Frodl et al., 2008) showing that the "s" allele is associated with reduced gray matter volumes in healthy adults. The opposite findings in the HR group are novel, however, with only a handful of studies reporting similar or consistent findings: One study reported, for example, that depressed patients with the homozygous La/La allelic combination (i.e. homozygous with the "L" allele for the 5-HTTLPR region and the "A" allele for the locus rs25531) had reduced gray matter volume compared with patients who had other genotypes (Frodl et al., 2008). Other studies(Li et al., 1997; Hu et al., 2000; Zill et al., 2000) of patients with Alzheimer's disease reported that the homozygous L/L genotype was associated with reduced gray matter volumes compared with those who had the "s" allele. In another study(Chorbov et al., 2007) of 58 female twins, where at least one had a lifetime history of MDD, and 63 healthy twins, the high activity "La" allelic combination elevated the risk for depression in the presence of moderate or severe trauma. Taken together, these prior studies suggest a significant effect of gene-by-population interaction on brain measures in which reduced gray matter volumes have been associated with the "s" allele in healthy populations, but with either the "L" allele or the "La" allelic combination within patient populations. Because our two risk groups differed statistically significantly in their lifetime history of depression (11 LR individuals, $42 \mathrm{HR}$ individuals, $\chi^{2}=13.96, \mathrm{~d} f=1$, Yates $P$-value $\left.=0.0002\right)$ and therefore are more like previous healthy or patient populations, the gene-by-population interaction suggested by the previous studies supports the significant effects of gene-by-risk interaction on cortical thickness in our cohort of participants.

\subsection{Serotonin and neural plasticity}

Several prior studies have suggested that neuronal plasticity is blunted in depression, likely because of the reduced serotonin signaling (Lee and Kim, 2010). Our findings of significantly greater variance in individuals who had the homozygous L/L genotype and significantly larger average thickness in LR/ll in contrast to the significantly smaller average thickness in HR/ll than in the " $\mathrm{s}$ " allele individuals suggests the presence of blunted response to familial risk that may be attributable to the presence of reduced neural plasticity associated with the "s" allele. The blunted neuroplastic response may derive from the neurotrophic role of serotonin in the developing brain (Azmitia, 2007; Daubert and Condron, 2010) and modulation of the cell adhesion molecules (Dalva et al., 2007) that are involved in connecting pre- and postsynaptic neurons, synaptic plasticity, and signal transmission. In fact, chronic treatment with SSRI such as fluoxetine has been shown to restore ocular dominance plasticity, recover visual function, and increased expression of brain derived neurotrophic factors in the visual cortex of adult rodents (Vetencourt, 2008). Furthermore, the delayed therapeutic effects of SSRI treatment may be due to the neuroplastic, physiological changes in spine and dendrite morphology as well as neurogenesis likely induced by the increased brain plasticity in response to increased serotonin signaling (Pittenger and Duman, 2008). Neuronal plasticity, however, is not modulated by a single gene but rather by epistatic effects of several genes, especially BDNF, with serotonin signaling likely playing an important role (Wilson et al., 1998; Gaspar et al., 2003; Mattson et al., 2004). Neuronal plasticity has been reported to decrease with reduced levels of BDNF in postmortem brains (Karege et al., 2005) and serum levels of BDNF(Sen et al., 2008) and has been quantified by the amplitude of visually evoked potential (Normann et al., 2007) of depressed patients. The inverse associations of the thickness with symptom severity (Fig. 6), extreme measures of thickness for the individuals with $\mathrm{L} / \mathrm{L}$ genotype, large variance in cortical thickness in individuals who had the homozygous $\mathrm{L} / \mathrm{L}$ genotype, and similar variance in the thickness for the HR/s and the LR/s individuals, suggested blunted neural plasticity in individuals with at least one "s" allele.

\subsection{Study limitations}

Although epistatic and/or environmental factors may have contributed to cortical thickening in the HR/s individuals compared with the HR/ll individuals, we could not assess these effects because epistatic and pathological environmental factors were not collected in the longitudinal study. The $\mathrm{HR} / \mathrm{s}$ individuals had 


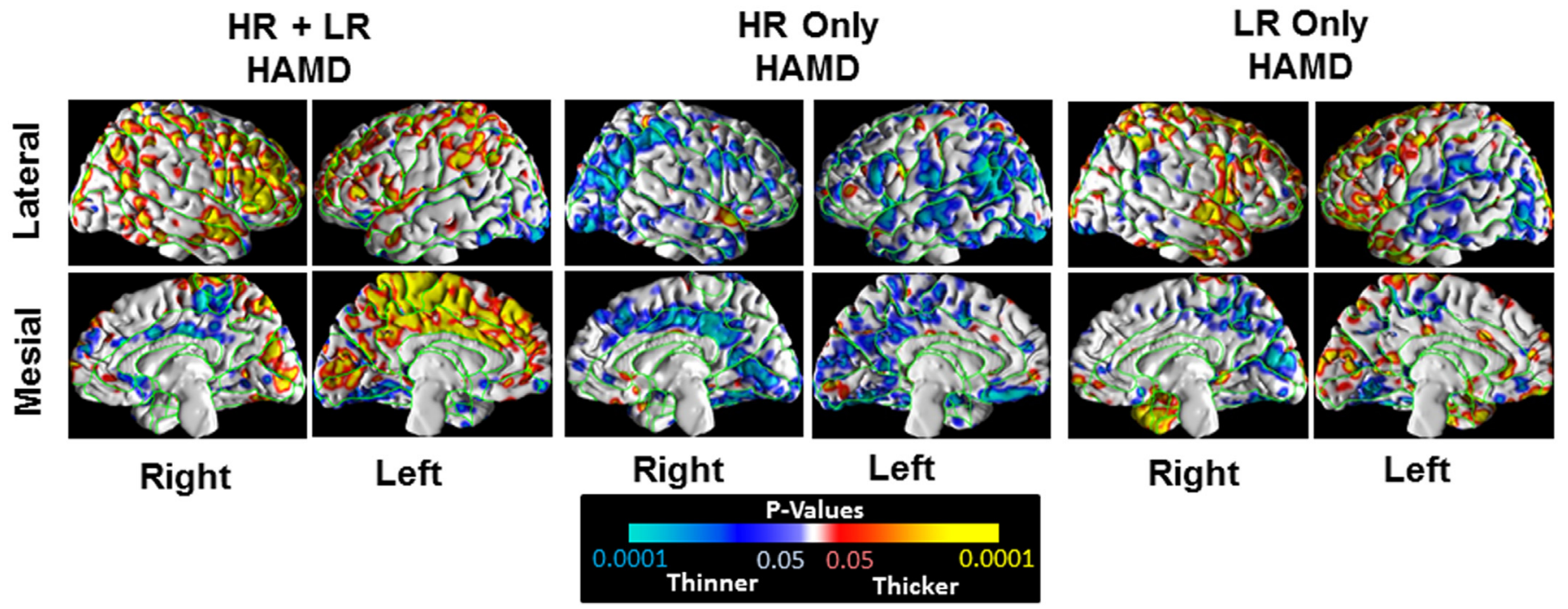

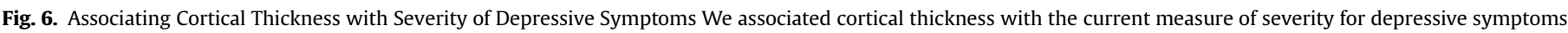

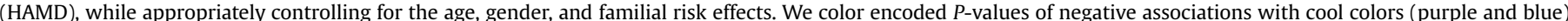

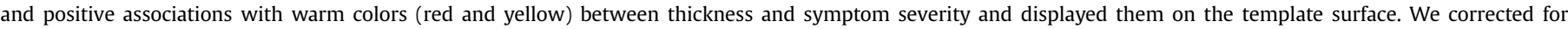

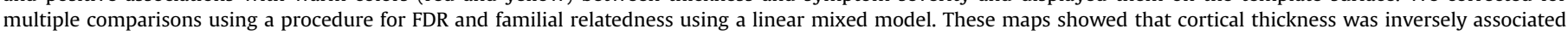

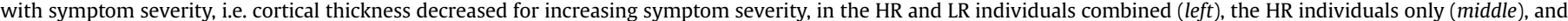

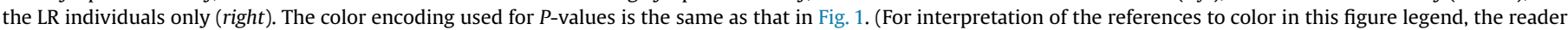
is referred to the web version of this article.)

thicker cortex likely due to interaction of the 5-HTTLPR with other shared genetic and/or environmental risk factors within the HR families. Identification of these shared factors that contributed to cortical thickening in interaction with the 5-HTTLPR genotype would likely require a study of larger number of individuals that assesses these additional pathological factors. Furthermore, the lack of statistical power to assess these factors was evident in the conditional process model (Supplemental results, Figs.S7 and S8) that showed although the cortex mediated the conditional risk effects on the behavioral measures of inattention and visual memory performance the mediating effects were small and diffusely distributed across the entire brain. In addition, the study cannot assess whether individuals with differing genotype had differing response to pathological environmental factors. Another limitation is that although IQ is associated with cortical thickness, IQ measures were available in only 52 participants and therefore we were unable to include this as a statistical covariate. Not controlling for the confounding effects of IQ of the cortex likely reduced our statistical power to detect gene effects on the cortex. The statistical power was further reduced because we did not control for comorbid disorders in our participants: 8 participants had Generalized Anxiety Disorder, 15 had Panic Disorder, 5 had Attention Deficit Disorder, and 8 had Obsessive Compulsive Disorder. Because the effects of comorbid disorders cannot be sufficiently modeled using the small number of individuals, we were unable to include them as a covariate in our analyses. Furthermore, although the findings in the HR (Fig. 2) and LR (Supplemental Fig. S3) individuals without lifetime history of depression matched closely with those in the entire cohort of individuals (Fig. 1), having lifetime depression may modulate the gene effects on cortical thickness across the two risk groups. However, we could not assess the modulation of gene effects due to small number of participants with lifetime history depression. Finally, the generalizability of these findings is limited to the families with grandparent with mild to severe depression. Despite these limitations, this is the first and one of the largest imaging genetic study that showed significant gene-by-risk effects on cortical thickness in individuals who were at either a low- or a high-familial risk for depression.

\subsection{Conclusions}

We showed that the 5-HTTLPR polymorphism modulated the effects of familial risk for depression on the cortex likely by modulating brain plasticity. The 5-HTTLPR polymorphism, however, explained only part of the variance and, likely, other genetic, epistatic, and/or environmental factors contributed additional variance to the risk endophenotype. Our results therefore suggested that strong effects of gene-by-risk interaction on the cortex likely through modulation of brain plasticity by altered serotonin signaling.

\section{Contributors}

RB performed all image and statistical analyses, interpreted analyses, and wrote the manuscript; BSP helped with study design, statistical analyses and their interpretations and writing of the manuscript; JG helped with interpretations and writing of the manuscript; $\mathbf{X H}$ helped with image analyses, generation of the figures, and editing the manuscript; $\mathbf{z O}$ helped with collection of the saliva, genotyping, and editing of the manuscript; $\mathbf{V W}$ helped with participant recruitment and writing of the manuscript; PJW helped with statistical analyses and editing of the manuscript; AT helped with participant recruitment, study design, and editing of the manuscript; MA helped with the interpretation of the analyses and editing of the manuscript; ASB helped with writing and editing of the manuscript; AS helped with interpretations of the analyses and writing of the manuscript; MMW helped with the establishment of the longitudinal high and low risk cohort, study design, following the cohort for 30 years, interpretation of the analyses, and writing of the manuscript.

\section{Conflict of interests}

Authors have no conflict of interests to report. 


\section{Acknowledgments}

This work was partially supported by National Institute of Mental Health Grant MH36197 (Myrna M. Weissman, P.I.) and Silvio O. Conte Center Grant, 1P50MH090966 (Jay Gingrich, P.I.).

\section{Appendix A. Supplementary material}

Supplementary data associated with this article can be found in the online version at http://dx.doi.org/10.1016/j.pscychresns.2016. 01.004.

\section{References}

Altshuler, L.L., Abulseoud, O.A., Foland-Ross, L., Bartzokis, G., Chang, S., Mintz, J. Hellemann, G., Vinters, H.V., 2010. Amygdala astrocyte reduction in subjects with major depressive disorder but not bipolar disorder. Bipolar Disord. 12, $541-549$.

Amos, C.I., 1994. Robust variance-components approach for assessing geneticlinkage in pedigrees. Am. J. Hum. Genet. 54, 535-543.

Anand, A., Li, Y., Wang, Y., Gardner, K., Lowe, M.J., 2007. Reciprocal effects of antidepressant treatment on activity and connectivity of the mood regulating circuit: an fMRI study. J. Neuropsychiatry Clin. Neurosci. 19, 274-282.

Anand, A., Li, Y., Wang, Y., Lowe, M.J., Dzemidzic, M., 2009. Resting state corticolimbic connectivity abnormalities in unmedicated bipolar disorder and unipolar depression. Psychiatry Res.- Neuroimaging 171, 189-198.

Anand, A., Li, Y., Wang, Y., Wu, J.W., Gao, S.J., Bukhari, L., Mathews, V.P., Kalnin, A., Lowe, M.J., 2005. Activity and connectivity of brain mood regulating circuit in depression: a functional magnetic resonance study. Biol. Psychiatry 57. 1079-1088.

Ansorge, M.S., Morelli, E., Gingrich, J.A., 2008. Inhibition of serotonin but not norepinephrine transport during development produces delayed, persistent perturbations of emotional behaviors in mice. J. Neurosci. 28, 199-207.

Ansorge, M.S., Zhou, M.M., Lira, A., Hen, R., Gingrich, J.A., 2004. Early-life blockade of the 5-HT transporter alters emotional behavior in adult mice. Science 306, $879-881$.

Antypa, N., Calati, R., Souery, D., Pellegrini, S., Sentissi, O., Amital, D., Moser, U. Montgomery, S., Kasper, S., Zohar, J., De Ronchi, D., Mendlewicz, J., Serretti, A., 2013. Variation in the HTR1A and HTR2A genes and social adjustment in depressed patients. J. Affect. Disord. 150, 649-652.

Azmitia, E.C., 2007. Serotonin and brain: evolution, neuroplasticity, and homeostasis. Pharmacol. Neurogenes. Neuroenhanc. 77, 31.

Bansal, R., Staib, L.H., Whiteman, R., Wang, Y.M., Peterson, B.S., 2005. ROC-based assessments of 3D cortical surface-matching algorithms. NeuroImage 24, $150-162$.

Benjamini, Y., 2010. Discovering the false discovery rate. J. R. Stat. Soc. B 72, 405-416.

Benjamini, Y., Hochberg, Y., 1995. Controlling the false discovery rate - a practical and powerful approach to multiple testing. J. R. Stat. Soc. B Methodol. 57, 289-300.

Bluhm, R., Williamson, P., Lanius, R., Theberge, J., Densmore, M., Bartha, R., Neufeld, R., Osuch, E., 2009. Resting state default-mode network connectivity in early depression using a seed region-of-interest analysis: Decreased connectivity with caudate nucleus. Psychiatry Clin. Neurosci. 63, 754-761.

Bora, E., Fornito, A., Pantelis, C., Yucel, M., 2012. Gray matter abnormalities in Major Depressive disorder: a meta-analysis of voxel based morphometry studies. J. Affect. Disord. 138, 9-18.

Caspi, A., Sugden, K., Moffitt, T.E., Taylor, A., Craig, I.W., Harrington, H., McClay, J. Mill, J., Martin, J., Braithwaite, A., Poulton, R., 2003. Influence of life stress on depression: moderation by a polymorphism in the 5-HTT gene. Science 301, 386-389.

Choi, J.E., Ha, T.H., Kim, J.H., Cha, B., Ha, K., 2008. Differences in brain structural abnormalities between bipolar disorder and major depressive disorder. Bipolar Disord, 10, 72

Chorbov, V.M., Lobos, E.A., Todorov, A.A., Heath, A.C., Botteron, K.N., Todd, R.D. 2007. Relationship of 5-HTTLPR genotypes and depression risk in the presence of trauma in a female twin sample. Am. J. Med. Genet. B 144B, 830-833.

Cole, J., Costafreda, S.G., McGuffin, P., Fu, C.H.Y., 2011. Hippocampal atrophy in first episode depression: a meta-analysis of magnetic resonance imaging studies. J. Affect. Disord. 134, 483-487.

Cox, D.R., Hinkley, D.V., 1979. Theoretical Statistics. Chapman and Hall; distributed in U.S. by Halsted Press, London, New York.

Dalva, M.B., McClelland, A.C., Kayser, M.S., 2007. Cell adhesion molecules: signalling functions at the synapse. Nat. Rev. Neurosci. 8, 206-220.

Daubert, E.A., Condron, B.G., 2010. Serotonin: a regulator of neuronal morphology and circuitry. Trends Neurosci. 33, 424-434.

Eley, T.C., Sugden, K., Corsico, A., Gregory, A.M., Sham, P., McGuffin, P., Plomin, R. Craig, I.W., 2004. Gene-environment interaction analysis of serotonin system markers with adolescent depression. Mol. Psychiatry 9, 908-915.
Endicott, J., Spitzer, R.L., Fleiss, J.L., Cohen, J., 1976. The global assessment scale. A procedure for measuring overall severity of psychiatric disturbance. Arch. Gen. Psychiatry 33, 766-771.

Esaki, T., Cook, M., Shimoji, K., Murphy, D.L., Sokoloff, L., Holmes, A., 2005. Developmental disruption of serotonin transporter function impairs cerebral responses to whisker stimulation in mice. Proc. Natl. Acad. Sci. USA 102, 5582-5587.

Frodl, T., Koutsouleris, N., Bottlender, R., Born, C., Jager, M., Morgenthaler, M., Scheuerecker, J., Zill, P., Baghai, T., Schule, C., Rupprecht, R., Bondy, B., Reiser, M., Moller, H.J., Meisenzahl, E.M., 2008. Reduced gray matter brain volumes are associated with variants of the serotonin transporter gene in major depression. Mol. Psychiatry 13, 1093-1101.

Gao, J., Pan, Z., Jiao, Z., Li, F., Zhao, G., Wei, Q, 2012. TPH2 Gene polymorphisms and major depression - a meta-analysis. PLoS ONE 7 (5), e36721.

Gaspar, P., Cases, O., Maroteaux, L., 2003. The developmental role of serotonin: news from mouse molecular genetics. Nat. Rev. Neurosci. 4, 1002-1012.

Glatz, K., Mossner, R., Heils, A., Lesch, K.P., 2003. Glucocorticoid-regulated human serotonin transporter (5-HTT) expression is modulated by the 5-HTT genepromotor-linked polymorphic region. J. Neurochem. 86, 1072-1078.

Goldberg, J.I., 1998. Serotonin regulation of neurite outgrowth in identified neurons from mature and embryonic Helisoma trivolvis. Perspect. Dev. Neurobiol. 5, $373-387$.

Hamilton, J.P., Siemer, M., Gotlib, I.H., 2008. Amygdala volume in major depressive disorder: a meta-analysis of magnetic resonance imaging studies. Mol. Psychiatry $13,993-1000$.

Hamilton, M., 1959. The assessment of anxiety-states by rating. Br. J. Med. Psychol. 32, 50-55.

Hamilton, M., 1967. Development of a rating scale for primary depressive illness. $\mathrm{Br}$ J. Soc. Clin. Psychol. 6, 278-296.

Haralick, R., Shapiro, L., 1992. Computer and Robot Vision volume 1. AddisonWesley Publishing Company, United States.

Hariri, A.R., Drabant, E.M., Munoz, K.E., Kolachana, B.S., Mattay, V.S., Egan, M.F., Weinberger, D.R., 2005. A susceptibility gene for affective disorders and the response of the human amygdala. Arch. Gen. Psychiatry 62, 146-152.

Hariri, A.R., Mattay, V.S., Tessitore, A., Kolachana, B., Fera, F., Goldman, D., Egan, M.F. Weinberger, D.R., 2002. Serotonin transporter genetic variation and the response of the human amygdala. Science 297, 400-403.

Haydon, P.G., Mccobb, D.P., Kater, S.B., 1987. the regulation of neurite outgrowth, growth cone motility, and electrical synaptogenesis by serotonin. J. Neurobiol 18, 197-215.

Heils, A., Teufel, A., Petri, S., Stober, G., Riederer, P., Bengel, D., Lesch, K.P., 1996. Allelic variation of human serotonin transporter gene expression. J. Neurochem. 66, 2621-2624.

Heils, A., Teufel, A., Petri, S., Seemann, M., Bengel, D., Balling, U., Riederer, P., Lesch, K.P., 1995. Functional promoter and polyadenylation site mapping of the human serotonin (5-HT) transporter gene. J. Neural Transm.-Gen. 102, 247-254.

Heinz, A., Braus, D.F., Smolka, M.N., Wrase, J., Puls, I., Hermann, D., Klein, S., Grusser S.M., Flor, H., Schumann, G., Mann, K., Buchel, C., 2005. Amygdala-prefrontal coupling depends on a genetic variation of the serotonin transporter. Nat. Neurosci. 8, 20-21.

Holmes, A., Li, O., Murphy, D.L., Gold, E., Crawley, J.N., 2003. Abnormal anxietyrelated behaviour in serotonin transporter null mutant mice: the influence of genetic background. Genes. Brain Behav. 2, 365-380.

Homberg, J.R. Schubert, D., Gaspar, P., 2010. New perspectives on the neurodevelopmental effects of SSRIs. Trends Pharmacol. Sci. 31, 60-65.

Hu, M., Retz, W., Baader, M., Pesold, B., Adler, G., Henn, F.A., Rosler, M., Thome, J. 2000. Promoter polymorphism of the 5-HT transporter and Alzheimer's disease. Neurosci. Lett. 294, 63-65.

Karege, F., Vaudan, G., Schwald, M., Perroud, N., La Harpe, R., 2005. Neurotrophin levels in postmortem brains of suicide victims and the effects of antemortem diagnosis and psychotropic drugs. Mol. Brain Res. 136, 29-37.

Kendler, K.S., Kuhn, J.W., Vittum, J., Prescott, C.A., Riley, B., 2005. The interaction of stressful life events and a serotonin transporter polymorphism in the prediction of episodes of major depression - a replication. Arch. Gen. Psychiatry 62 $529-535$.

Kobiella, A., Reimold, M., Ulshofer, D.E., Ikonomidou, V.N., Vollmert, C., VollstadtKlein, S., Rietschel, M., Reischl, G., Heinz, A., Smolka, M.N., 2011. How the serotonin transporter 5-HTTLPR polymorphism influences amygdala function: the roles of in vivo serotonin transporter expression and amygdala structure. Transl. Psychiatry 1, e37.

Leckman, J.F., Sholomskas, D., Thompson, D., Belanger, A., Weissman, M., 1982. Best estimate of lifetime psychiatric diagnosis: a methodological study. Arch. Gen. Psychiatry 39, 879-883.

Lee, B.H., Kim, Y.K., 2010. The Roles of BDNF in the pathophysiology of major depression and in antidepressant treatment. Psychiatry Investig. 7, 231-235.

Lehmann, E.L., Romano, J.P., 2005. Testing Statistical Hypotheses, 3rd ed Springer, New York.

Lesch, K.P. Mossner, R., 1998. Genetically driven variation in serotonin uptake: Is there a link to affective spectrum, neurodevelopmental, and neurodegenerative disorders? Biol. Psychiatry 44, 179-192.

Li, T., Holmes, C., Sham, P.C., Vallada, H., Birkett, J., Kirov, G., Lesch, K.P., Powell, J. Lovestone, S. Collier, D., 1997. Allelic functional variation of serotonin transporter expression is a susceptibility factor for late onset Alzheimer's disease. Neuroreport 8, 683-686.

Lira, A., Zhou, M.M., Castanon, N., Ansorge, M.S., Gordon, J.A., Francis, J.H., BradleyMoore, M., Lira, J., Underwood, M.D., Arango, V., Kung, H.F., Hofer, M.A., Hen, R. 
Gingrich, B., 2003. Altered depression-related behaviors and functional changes in the dorsal raphe nucleus of serotonin transporter-deficient mice. Biol. Psychiatry 54, 960-971.

Lorenzetti, V., Allen, N.B., Fornito, A., Yucel, M., 2009. Structural brain abnormalities in major depressive disorder: a selective review of recent MRI studies. J. Affect. Disord. 117, 1-17.

Mann, J.J., 1999. Role of the serotonergic system in the pathogenesis of major depression and suicidal behavior. Neuropsychopharmacology 21, S99-S105.

Mannuzza, S., Fyer, A.J., Klein, D.F., Endicott, J., 1986. Schedule for affective-disorders and schizophrenia-lifetime version modified for the study of anxiety disorders (Sads-La)-rationale and conceptual development. J. Psychiatr. Res. 20, 317-325.

Masi, G., Brovedani, P., 2011. The hippocampus, neurotrophic factors and depression possible implications for the pharmacotherapy of depression. CNS Drugs 25 913-931.

Mattson, M.P., Maudsley, S., Martin, B., 2004. BDNF and 5-HT: a dynamic duo in agerelated neuronal plasticity and neurodegenerative disorders. Trends Neurosci. 27, 589-594.

Mazziotta, J., Toga, A., Evans, A., Fox, P., Lancaster, J., Zilles, K., Woods, R., Paus, T., Simpson, G., Pike, B., Holmes, C., Collins, L., Thompson, P., MacDonald, D., Iacoboni, M., Schormann, T., Amunts, K., Palomero-Gallagher, N., Geyer, S., Parsons, L., Narr, K., Kabani, N., Le Goualher, G., Boomsma, D., Cannon, T., Kawashima, R., Mazoyer, B., 2001. A probabilistic atlas and reference system for the human brain: International Consortium for Brain Mapping (ICBM). Philos. Trans. R. Soc. Lond. Behav. Neurosci. 356, 1293-1322.

Normann, C., Schmitz, D., Furmaier, A., Doing, C., Bach, M., 2007. Long-term plasticity of visually evoked potentials in humans is altered in major depression. Biol. Psychiatry 62, 373-380.

Perrin, S., Last, C.G., 1992. Do childhood anxiety measures measure anxiety? J. Abnorm. Child Psychol. 20, 567-578.

Peterson, B.S., Warner, V., Bansal, R., Zhu, H., Hao, X., Liu, J., Durkin, K., Adams, P.B. Wickramaratne, P., Weissman, M.M., 2009. Cortical thinning in persons at increased familial risk for major depression. Proc. Natl. Acad. Sci. USA 106, 6273-6278.

Pezawas, L., Meyer-Lindenberg, A., Drabant, E.M., Verchinski, B.A., Munoz, K.E., Kolachana, B.S., Egan, M.F., Mattay, V.S., Hariri, A.R., Weinberger, D.R., 2005. 5 HTTLPR polymorphism impacts human cingulate-amygdala interactions: a genetic susceptibility mechanism for depression. Nat. Neurosci. 8, 828-834.

Pittenger, C., Duman, R.S., 2008. Stress, depression, and neuroplasticity: a convergence of mechanisms. Neuropsychopharmacology 33, 88-109.

Plessen, K.J., Bansal, R., Zhu, H., Whiteman, R., Quackenbush, G.A., Hugdahl, K., Peterson, B.S., 2006. Hippocampus and amygdala morphology in AttentionDeficit/Hyperactivity Disorder. Arch. Gen. Psychiatry 63, 795-807.

Poznanski, E.O., Freeman, L.N., Mokros, H.B., 1985. Children's depression rating scale revised. Psychopharmacol. Bull. 21, 979-989.

Rosenfeld, A., Kak, A.C., 1982. Digital Picture Processing. Academic Press, Inc., New York.

Sandman, C.A. Buss, C., Head, K., Davis, E P., 2015. Fetal exposure to maternal depressive symptoms is associated with cortical thickness in late childhood. Biol Psychiatry 77, 324-334.

Sen, S., Duman, R., Sanacora, G., 2008. Serum brain-derived neurotrophic factor, depression, and antidepressant medications: meta-analyses and implications. Biol. Psychiatry 64, 527-532.

Shaffer, D., Gould, M.S., Brasic, J., Ambrosini, P., Fisher, P., Bird, H., Aluwahlia, S. 1983. A children's global assessment scale (CGAS). Arch. Gen. Psychiatry 40
$1228-1231$.

Shattuck, D.W., Leahy, R.M., 2002. BrainSuite: an automated cortical surface identification tool. Med. Image Anal. 8, 129-142.

Sheline, Y.I., Price, J.L., Yan, Z.Z., Mintun, M.A., 2010. Resting-state functional MRI in depression unmasks increased connectivity between networks via the dorsal nexus. Proc. Natl. Acad. Sci. USA 107, 11020-11025.

Shrout, P.E., Fleiss, J.L., 1979. Intraclass correlations: uses in assessing rater reliability. Psychol. Bull. 86, 420-428.

Sled, G.J., Zijdenbos, A.P., Evans, A.C., 1998. A nonparametric method for automatic correction of intensity nonuniformity in MRI data. IEEE Trans. Med. Imaging 17, $87-97$.

Thomas, D.C., 2004. Statistical Methods in Genetic Epidemiology. Oxford University Press, New York

Tzeng, D.S., Chien, C.C., Lung, F.W., Yang, C.Y., 2009. MAOA Gene polymorphisms and response to mirtazapine in major depression. Hum. Psychopharm. Clin. 24, 293-300.

Vetencourt, J.F.M., 2008. The antidepressant fluoxetine restores plasticity in the adult visual cortex. Science 320, 385 1588-1588.

Weissman, M.M., Wickramaratne, P., Nomura, Y., Warner, V., Pilowsky, D., Verdeli, H., 2006. Offspring of depressed parents: 20 years later. Am. J. Psychiatry 163, 1001-1008.

Weissman, M.M., Gammon, G.D., John, K., Merikangas, K.R., Warner, V., Prusoff, B.A., Sholomskas, D., 1987. Children of depressed parents. Arch. Gen. Psychiatry 44, $847-853$.

Weissman, M.M., Wickramaratne, P., Nomura, Y., Warner, V., Verdeli, H., Pilowsky, D.J., Grillon, C., Bruder, G., 2005a. Families at high and low risk for depression. Arch. Gen. Psychiatry 62, 29-36.

Weissman, M.M., Wickramaratne, P. Nomura, Y, Warner, V Verdeli, H, Pilowsky, D.J., Grillon, C., Bruder, G., 2005b. Families at high and low risk for depression-A 3-generation study. Arch. Gen. Psychiatry 62, 29-36.

Wendland, J.R., Martin, B.J., Kruse, M.R., Lesch, K.P., Murphy, D.L., 2006. Simultaneous genotyping of four functional loci of human SLC6A4, with a reappraisal of 5-HTTLPR and rs25531. Mol. Psychiatry 11, 224-226.

Whitakerazmitia, P.M., Azmitia, E.C., 1986. Autoregulation of fetal serotonergic neuronal development-role of high-affinity serotonin receptors. Neurosci. Lett. 67, 307-312..

White, K.J., Walline, C.C., Barker, E.L., 2005. Serotonin transporters: implications for antidepressant drug development. AAPS J. 7, E421-E433.

Wilhelm, K., Mitchell, P.B., Niven, H., Finch, A., Wedgwood, L., Scimone, A., Blair, I.P., Parker, G., Schofield, P.R., 2006. Life events, first depression onset and the serotonin transporter gene. Br. J. Psychiatry 188, 210-215.

Wilson, C.C., Faber, K.M., Haring, J.H., 1998. Serotonin regulates synaptic connections in the dentate molecular layer of adult rats via 5-HT1a receptors: evidence for a glial mechanism. Brain Res. 782, 235-239.

Zalsman, G., Huang, Y.Y., Oquendo, M.A., Burke, A.K., Hu, X.Z., Brent, D.A., Ellis, S.P. Goldman, D., Mann, J.J., 2006. Association of a triallelic serotonin transporter gene promoter region (5-HTTLPR) polymorphism with stressful life events and severity of depression. Am. J. Psychiatry 163, 1588-1593.

Zhu, H., Li, Y., Tang, N., Bansal, R., Hao, X., Weissman, M.M., Peterson, B.G., 2008. Statistical modelling of brain morphological measures within family pedigrees. Stat. Sin. 18, 1569-1591.

Zill, P., Padberg, F., de Jonge, S., Hampel, H., Burger, K., Stubner, S., Boetsch, T., Moller, H.J., Ackenheil, M., Bondy, B., 2000. Serotonin transporter (5-HTT) gene polymorphism in psychogeriatric patients. Neurosci. Lett. 284, 113-115. 